\title{
PENGARUH OLAHRAGA BERSEPEDA DALAM MENURUNKAN DERAJAT DISMENORE PADA MAHASISWI FAKULTAS KEDOKTERAN UNIVERSITAS MUHAMMADIYAH MALANG ANGKATAN 2008
}

\author{
Masrida Fatmawati' ${ }^{1}$, Anissa' Hasanah $^{2}$, Isbandiyah ${ }^{3}$ \\ Fakultas Kedokteran Universitas Muhammadiyah Malang, J1. Bendungan Sutami No. 188A, Kota Malang, \\ 65145, Indonesia, (0341) 551149
}

\begin{abstract}
ABSTRAK
Pengaruh Olahraga Bersepeda Dalam Menurunkan Derajat Dismenore pada Mahasiswi Fakultas Kedokteran Universitas Muhammadiyah Malang Angkatan 2008. Latar Belakang: Dismenore banyak dialami wanita. Di Indonesia angka kejadian dismenore sebesar 64,25\%. Bersepeda merupakan salah satu pengobatan non-medikamentosa yang menurunkan derajat dismenore. Tujuan: Mengetahui pengaruh olahraga bersepeda dalam menurunkan derajat dismenore. Metode: Penelitian dilakukan bulan Februari - Maret 2012, menggunakan metode observasi analitik pendekatan secara kohort. Sampel penelitian 38 mahasiswi dan dibagi menjadi 2 kelompok, kelompok perlakuan olahraga bersepeda selama 1 bulan dan kelompok kontrol tanpa olahraga bersepeda. Hasil: Analisis menggunakan uji-t berpasangan. Hasil penelitian menunjukkan nilai t- hitung 7,398, dan nilai signifikansi 0,000 yang artinya terdapat pengaruh olahraga bersepeda dalam menurunkan derajat dismenore. Hasil perhitungan menggunakan uji korelasi rank didapatkan hasil sebesar $66,3 \%$ yang artinya besar pengaruh olahraga bersepeda dalam menurunkan derajat dismenore sebesar 66,3\%. Insiden dismenore mahasiswi Fakultas Kedokteran Universitas Muhammadiyah Malang angkatan 2008 sebesar 62,5\% dari 72 mahasiswi. Derajat dismenore terbanyak sebelum melakukan olahraga bersepeda adalah derajat sedang (skala 6 VAS), 31,6\% untuk kelompok perlakuan dan 36,8\% untuk kelompok kontrol. Derajat dismenore terbanyak setelah melakukan olahraga bersepeda adalah derajat ringan (skala 2 VAS) sebesar 47,7\% untuk kelompok perlakuan dan derajat sedang sebesar 42,1\% untuk kelompok kontrol. Kesimpulan: Olahraga bersepeda berpengaruh dalam penurunan derajat dismenore pada mahasisiwi Fakultas Kedokteran Universitas Muhammadiyah Malang angkatan 2008.
\end{abstract}

\begin{abstract}
Effect of Bike Riding in Reducing Reduce Dysmenorrhea Degree among Female Students of 2008 in Faculty of Medicine University of Muhammadiyah Malang. Background: Dysmenorrhea is experienced by a lot of women. In Indonesia, the incidence of dysmenorrhea is $64,25 \%$. Bike riding is one of non-medicinal treatment that can potentially reduce dysmenorrhea degree. Objective : This research was aimed to investigate the effect of bike riding to reduce dysmenorrhea degree. Method : Research was carried out over February to March 2012, analytic observational method with cohort approach was used in this research. Eligible sample was 38 female students that were then split into 2 groups, one group was treatment group which had bike riding activity for one month and was as control group the other one that without bike riding activity. Result : Data was analyzed using paired $t$ test. The result then showed t value 7,398 with significance value 0,000 which indicated that there was the effect of bike riding activity in reducing dysmenorrhea degree. Analysis with rank correlation test resulted in 66,3\% which meant that bike riding could effect in reducing dysmenorrbea degree by 66,3\%. The incidence of dysmenorrbea among female students of 2008 in Faculty of Medicine University of Muhammadiyah Malang was 62,5\% out of total 72 female students. Most reported dysmenorrhea degree before having bike riding was moderate ( 6 in VAS scale), 31,6\% in treatment group and 36,8\% in control group. After having bike riding, the most reported degree was mild (2 in VAS scale), 417,7\% in treatment group, while moderate degree was reported among control group that was $42,1 \%$. Conclusion: Bike riding effects in reducing dysmenorrhea degree among female students 2008 in Faculty of Medicine University of Muhammadiyah Malang.
\end{abstract}

Key words: bike riding, dysmenorrhea degree, female students 2008 in Faculty of Medicine University of Muhammadiyah Malang

\section{PENDAHULUAN}

Menstruasi merupakan bagian dari proses reguler yang mempersiapkan tubuh wanita setiap bulannya untuk kehamilan. Usia remaja putri pada waktu pertama kalinya muncul menstruasi (menarche) bervariasi lebar, yaitu antara 10-16 tahun, tetapi rata-ratanya 12,5 tahun (Wijayanti, 2009).
Walaupun menstruasi datang setiap bulan pada usia reproduksi, banyak wanita yang mengalami ketidaknyamanan fisik saat menjelang atau selama haid berlangsung. Salah satu ketidaknyamanan fisik saat menstruasi yaitu dismenore (Chudnoff, 2005). 
Dismenore (nyeri haid) adalah nyeri yang timbul akibat kontraksi disritmik endometrium yang menimbulkan gejala, mulai dari nyeri ringan sampai berat pada perut bagian bawah (Baziad, 2005). Dismenore dibagi menjadi primer dan sekunder Dismenore primer didefinisikan sebagai nyeri menstruasi pada wanita dengan anatomi pelvik yang normal dan biasanya dimulai pada masa remaja (French, 2005). Dismenore sekunder didefinisikan sebagai nyeri menstruasi yang diakibatkan adanya anatomi ataupun makroskopik yang patologis dari pelvik. Kondisi yang paling sering terjadi pada wanita usia 30-45 tahun (Calis, Popat, Devra, dan Kalantaridou, 2009).

Dismenore banyak dialami oleh para wanita. Di Amerika Serikat diperkirakan antara $20-90 \%$ wanita mengalami dismenore, dan 10-15\% diantaranya mengalami dismenore berat (Annathayakheisha, 2009), dan 75-85\% wanita yang mengalami dismenore ringan (Abbaspour, 2006). Telah diperkirakan bahwa lebih dari 140 juta jam kerja hilang setiap tahunnya di Amerika Serikat karena dismenore primer (French, 2005). Sebuah studi longitudinal secara kohort pada wanita Swedia ditemukan prevalensi dismenore adalah $90 \%$ pada wanita usia 19 tahun dan $67 \%$ pada wanita usia 24 tahun. Sepuluh persen dari wanita usia 24 tahun yang dilaporkan tersebut mengalami nyeri yang sampai mengganggu kegiatan sehari-hari (Chudnoff, 2005). Di Indonesia angka kejadian dismenore sebesar 64,25\% yang terdiri dari $54,89 \%$ dismenore primer dan $9,36 \%$ dismenore sekunder (Widjanarko, 2006). Di Surabaya di dapatkan 1,07 $\%-1,31 \%$ dari jumlah penderita dismenore datang kebagian kebidanan (Warianto, 2008).

Mengatasi dismenore dapat dilakukan dengan terapi medikamentosa maupun non-medikamentosa, secara medikamentosa dapat diberikan obat OAINS (obat antiinflamasi non steroid) yang menghambat pembentukan prostaglandin seperti ibuprofen, naproksen, asam mefenamat dan kontrasepsi oral. Sedangkan pengobatan nonmedikamentosa dapat dilakukan dengan pembedahan, thermoablasi, perbaikan nutrisi, dan salah satunya dengan olahraga. Hal ini disebabkan saat melakukan olahraga aerobik tubuh akan menghasilkan hormon endorpbine yang dihasilkan di otak dan susunan syaraf tulang belakang. Hormon ini dapat berfungsi sebagai obat penenang alami yang diproduksi otak sehingga menimbulkan rasa nyaman (Harry, 2007). Dari hasil penelitian ternyata dismenore lebih sedikit terjadi pada olahragawati dibandingkan wanita yang tidak melakukan olahraga (Izzo \& Labriola, 1991). Bersepeda merupakan salah satu olahraga yang menggunakan proses penggunaan energi secara aerobik. Bersepeda adalah cara yang baik untuk melatih pernapasan, kerja jantung dan kebugaran otot. Selain itu bersepeda memiliki keindahan bahwa dapat lebih memperkuat tubuh dan jiwa secara simultan (Burke \& Edmund R, 1996 ). Menurut Moeloek (1984) bersepeda dapat meningkatkan pasokan darah dan oksigen sehingga akan memperlancar peredaran darah ke organ reproduksi yang mengalami vasokonstriksi, yang akan menyebabkan terjadinya penurunan derajat dismenore.

Fakultas Kedokteran Universitas Muhammadiyah Malang merupakan salah satu Fakultas Kedokteran Universitas swasta di kota Malang. Berdasarkan observasi pendahuluan terdapat komunitas sepeda pada mahasiswa
Fakultas Kedokteran Universitas Muhammadiyah Malang angkatan 2008, sedangkan pada angkatan lain Fakultas Kedokteran Universitas Muhammadiyah Malang tidak terdapat komunitas sepeda dan juga didapatkan bahwa sebesar 62,5\% dari total 72 mahasiswi Fakultas Kedokteran Universitas Muhammadiyah Malang angkatan 2008 mengalami dismenore yang dapat mengganggu aktivitas sehari-hari. Berdasarkan data diatas maka perlu adanya penelitian untuk mencari alternatif terapi yang mudah dilakukan untuk menurunkan derajat dismenore. Hal tersebut mendasari penulis melakukan penelitian yang berjudul "Pengaruh Olahraga Bersepeda Dalam Menurunkan Derajat Dismenore Pada Mahasiswi Fakultas Kedokteran Universitas Muhammadiyah Malang Angkatan 2008".

\section{METODE}

Rancangan penelitian yang dipergunakan adalah observasi analitik dengan pendekatan secara kohort. Penelitian ini dimulai dengan mengidentifikasi kelompok dengan resiko tertentu (dismenore) kemudian secara prospektif diteliti faktor penyembuhan (efek olahraga bersepeda dengan frekuensi 2-3x/minggu, durasi 30-60 menit setiap kali berolahraga sepeda selama 1 bulan terhadap penurunan derajat dismenore) yang mungkin dapat menerangkan mengapa ada kelompok perlakuan terkena efek dan yang kontrol tidak terkena efek.

Penelitian ini dilakukan di kota Malang selama bulan Februari 2012- Maret 2012. Populasi penelitian ini adalah mahasiswi Fakultas Kedokteran Universitas Muhammadiyah Malang angkatan 2008 yang mengalami dismenore saat menstruasi. Sampel penelitian ini adalah semua/ populasi mahasiswi Fakultas Kedokteran Universitas Muhammadiyah Malang angkatan 2008 yang mengalami dismenore saat menstruasi. Pengambilan sampel dilakukan dengan metode total sampling dimana seluruh populasi menjadi anggota yang akan diamati sebagai sampel.

Kriteria inklusi kelompok perlakuan dalam penelitian ini adalah mahasiswi Fakultas Kedokteran Universitas Muhammadiyah Malang angkatan 2008 yang sudah mengalami menstruasi, siklus menstruasi yang teratur dalam 6 bulan terakhir, lamanya setiap siklus menstruasi 21 sampai 35 hari, yang mengalami dismenore, dan mengikuti club olahraga bersepeda/ yang memiliki sepeda yang bersedia melakukan olahraga bersepeda.

Kriteria ekslusi kelompok perlakuan dalam penelitian ini adalah mahasiswi Fakultas Kedokteran Universitas Muhammadiyah Malang angkatan 2008 yang mengalami dismenore namun tidak bersedia/ menolak menjadi objek penelitian, mengkonsumsi obat OAINS (obat anti-inflamasi non steroid) seperti ibuprofen, naproksen, asam mefenamat atau obat dismenore yang dijual di pasaran seperti kiranti, feminax, sedang menggunakan kontrasepsi oral saat terjadinya dismenore, dan melakukan olahraga anaerobik serta olahraga aerobik selain olahraga bersepeda seperti renang, lari, dan jalan cepat.

Kriteria inklusi kelompok kontrol dalam penelitian ini adalah mahasiswi Fakultas Kedokteran Universitas Muhammadiyah Malang angkatan 2008 yang sudah mengalami menstruasi, siklus menstruasi yang teratur dalam 
6 bulan terakhir, lamanya setiap siklus menstruasi 21 sampai 35 hari, yang mengalami dismenore, dan bersedia menjadi objek penelitian namun tidak mengikuti club olahraga bersepeda/ yang tidak memiliki sepeda, yang tidak mau melakukan olahraga bersepeda.

Kriteria eksklusi kelompok kontrol dalam penelitian ini adalah mahasiswi Fakultas Kedokteran Universitas Muhammadiyah Malang angkatan 2008 yang mengalami dismenore namun tidak bersedia/ menolak menjadi objek penelitian, mengkonsumsi obat OAINS (obat anti-inflamasi non steroid) seperti ibuprofen, naproksen, asam mefenamat atau obat dismenore yang dijual di pasaran seperti kiranti, feminax, sedang menggunakan kontrasepsi oral saat terjadinya dismenore, dan melakukan olahraga anaerobik serta olahraga aerobik selain olahraga bersepeda seperti renang, lari, dan jalan cepat.

Terdapat dua variabel dalam penelitian ini. Variabel bebas yaitu olahraga bersepeda. Variabel tergantung yaitu derajat dismenore.

Instrumen pengumpulan data yang digunakan dalam penelitian ini adalah kuesioner. Kuesioner terdiri dari kuesioner 1 dan kuesioner 2. Kuisioner 1 digunakan untuk memilih kriteria inklusi dan kriteria eksklusi. Kuisioner 2 digunakan untuk melihat data dismenore sebelum dan setelah melakukan olahraga bersepeda. Selain kuesioner juga digunakan skala nyeri analog visual (Visual Analog Scale, VAS). Skala nyeri analog visual (Visual Analog Scale, VAS) menampilkan tingkatan nyeri 0-10 dan ekspresi wajah yang ditampilkan untuk mengetahui dan mendeskripsikan lebih mendalam tentang derajat dismenore mahasiswi (Kristiono,2007).

Data primer yang diperoleh dari hasil pengukuran diolah terlebih dahulu dalam bentuk tabel distribusi frekuensi dan diagram. Untuk mengetahui pengaruh dan besar pengaruh olahraga bersepeda dalam menurunkan derajat dismenore pada mahasiswi Fakultas Kedokteran Universitas Muhammadiyah Malang angkatan 2008, data tersebut dianalisis dengan uji t-berpasangan dan uji korelasi rank menggunakan program komputer SPSS for 17.0 for Windows.

\section{HASIL DAN PEMBAHASAN}

Jumlah sampel mahasiswi yang mengalami dismenore sebanyak 45 atau sebesar $62,5 \%$ dari total 72 mahasiswi, namun yang termasuk dalam kriteria inklusi hanya 38 mahasiswi. Dari 38 sampel mahasiswi, dibagi menjadi 2 kelompok yaitu kelompok perlakuan (19 mahasiswi yang tersedia waktu dan telah melakukan olahraga bersepeda selama 1 bulan) dan kelompok kontrol (19 mahasiswi tanpa dan atau yang tidak tersedia waktu melakukan olahraga bersepeda). Masing-masing kelompok kemudian diberikan kuisioner pretest dan postest yang telah diuji validitas dan reabilitas untuk mengetahui pengaruh olahraga bersepeda dan perbedaan antara kelompok perlakuan sebelum dan setelah melakukan olahraga bersepeda selama 1 bulan dengan kelompok kontrol tanpa melakukan olahraga bersepeda.
Tabel 1. Deskripsi Karekteristik Derajat Dismenore Mahasiswi Sebelum Malakukan Olahraga Bersepeda

\begin{tabular}{l|l|l}
\hline $\begin{array}{c}\text { Dismenore } \\
\text { sebelum }\end{array}$ & Perlakuan & \multicolumn{1}{|c}{ Kontrol } \\
\hline $\begin{array}{l}\text { Skala 2 } \\
\text { (Ringan) }\end{array}$ & $1(5,2 \%)$ & $1(5,2 \%)$ \\
\hline $\begin{array}{l}\text { Skala 4 } \\
\text { (Sedang) }\end{array}$ & $4(21 \%)$ & $6(31,6 \%)$ \\
\hline $\begin{array}{l}\text { Skala 6 } \\
\text { (Sedang) }\end{array}$ & $6(31,6 \%)$ & $7(36,8 \%)$ \\
\hline $\begin{array}{l}\text { Skala 8 } \\
\text { (Berat) }\end{array}$ & $5(26,4 \%)$ & $4(21 \%)$ \\
\hline $\begin{array}{l}\text { Skala 10 } \\
\text { Berat }\end{array}$ & $3(15,8 \%)$ & $1(5,2 \%)$ \\
\hline Total & $19(100 \%)$ & $19(100 \%)$ \\
\hline
\end{tabular}

\section{Derajat Dismenore Sebelum}

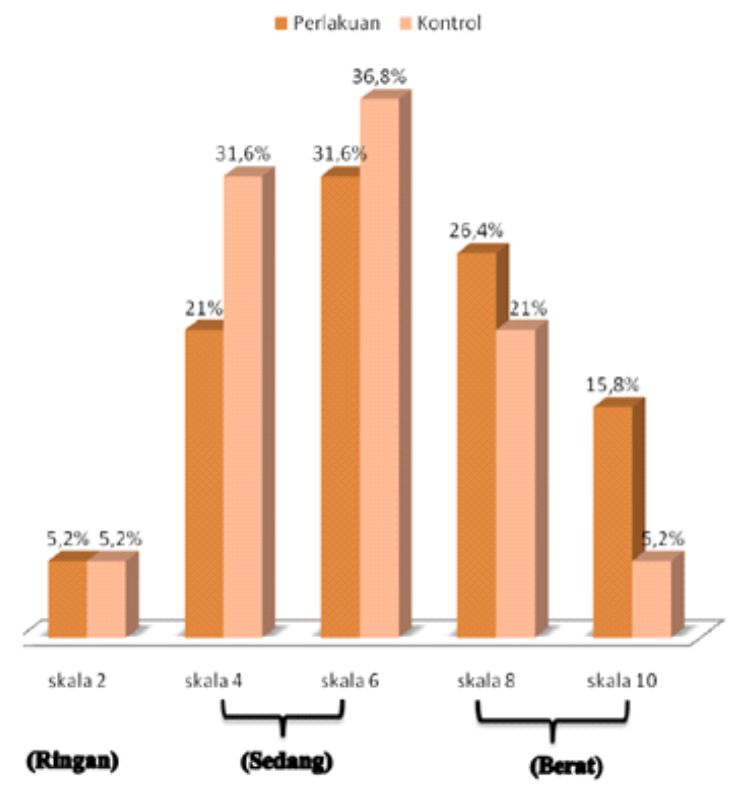

Gambar 1. Derajat Dismenore Mahasiswi Sebelum Malakukan Olahraga Bersepeda

Data diatas merupakan gambaran derajat dismenore sebelum melakukan olahraga bersepeda. Kelompok perlakuan dan kelompok kontrol banyak mengalami dismenore derajat sedang dengan prosentase sebesar 31,6\% atau sebanyak 6 mahasiswi pada skala 6 kartu VAS untuk kelompok perlakuan dan 36,8\% atau sebanyak 7 mahasiswi pada skala 6 kartu VAS untuk kelompok kontrol. 
Tabel 2. Deskripsi Karekteristik Derajat Dismenore Mahasiswi Setelah Malakukan Olahraga Bersepeda

\begin{tabular}{l|l|l}
\hline \multicolumn{1}{c|}{$\begin{array}{c}\text { Dismenore } \\
\text { setelah }\end{array}$} & Perlakuan & \multicolumn{1}{c}{ Kontrol } \\
\hline $\begin{array}{l}\text { Skala 2 } \\
\text { (Ringan) }\end{array}$ & $9(47,7 \%)$ & $2(10,5 \%)$ \\
\hline $\begin{array}{l}\text { Skala 4 } \\
\text { (Sedang) }\end{array}$ & $1(5,2 \%)$ & $4(21 \%)$ \\
\hline $\begin{array}{l}\text { Skala 6 } \\
\text { (Sedang) }\end{array}$ & $8(42,1 \%)$ & $8(42,1 \%)$ \\
\hline $\begin{array}{l}\text { Skala 8 } \\
\text { (Berat) }\end{array}$ & $1(5,2 \%)$ & $4(21 \%)$ \\
\hline Skala 10 Berat & $0(0 \%)$ & $1(5,2 \%)$ \\
\hline Total & $19(100 \%)$ & $19(100 \%)$ \\
\hline
\end{tabular}

\section{Derajat Dismenore Setelah}

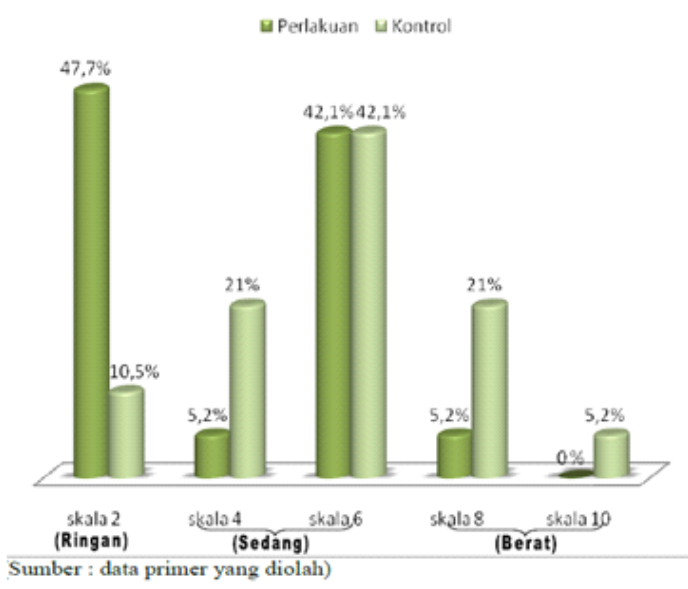

Gambar 2. Derajat Dismenore Mahasiswi Setelah Malakukan Olahraga Bersepeda

Dari tabel dan histogram diatas didapatkan bahwa pada kelompok perlakuan setelah melakukan olahraga bersepeda secara rutin, sebesar $47,7 \%$ atau sebanyak 9 mahasiswi derajat dismenore yang paling banyak dialami adalah derajat ringan yaitu pada skala 2 kartu VAS. Sedangkan pada kelompok kontrol sebesar $42,1 \%$ atau sebanyak 8 mahasiswi masih banyak mengalami dismenore derajat sedang yaitu pada skala 6 kartu VAS.

Tabel 3. Deskripsi Pengaruh Olahraga Bersepeda Dalam Menurunkan Derajat

Dismenore Pada Mahasiswi Fakultas Kedokteran Universitas Muhammadiyah Malang Angkatan 2008

\begin{tabular}{l|l|l}
\hline $\begin{array}{l}\text { Derajat } \\
\text { Dismenore }\end{array}$ & Perlakuan & Kontrol \\
\hline Menurun & $15(78,9 \%)$ & $2(10,5 \%)$ \\
\hline Tetap & $4(21 \%)$ & $16(84,2 \%)$ \\
\hline Bertambah & $0(0 \%)$ & $1(5,3 \%)$ \\
\hline Total & $19(100 \%)$ & $19(100 \%)$ \\
\hline
\end{tabular}

\section{Pengaruh Olahraga Bersepeda Dalam} Menurunkan Derajat Dismenore

Q Perlakuan $\square$ kontrol

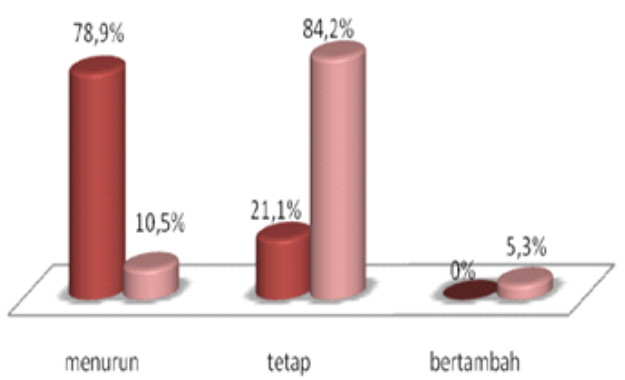

Gambar 3. Pengaruh Olahraga Bersepeda Dalam Menurunkan Derajat Dismenore

Dari data diatas, dapat diketahui perbedaan antara kelompok perlakuan dan kelompok kontrol, dimana pada kelompok perlakuan sebesar $78,9 \%$ atau sebanyak 15 mahasiswi mengalami penurunan derajat dismenore sedangkan pada kelompok kontrol sebesar 84,2\% atau sebanyak 16 mahasiswi derajat dismenore yang dialami tetap.

\section{Tabel 4. Tabel Deskripsi Penurunan Derajat Dismenore}

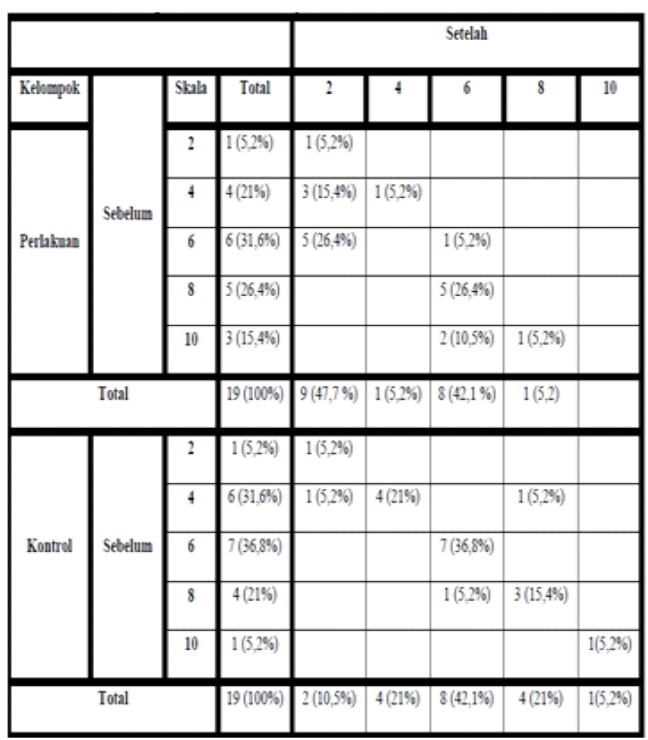

Tabel diatas merupakan deskripsi penurunan derajat dismenore sebelum dan setelah melakuan olahraga bersepeda. Berdasarkan tabel tersebut diatas didapatkan gambaran bahwa pada kelompok perlakuan banyak yang mengalami penurunan derajat dismenore, sedangkan pada kelompok kontrol cenderung tetap.

Pengujian hipotesis dengan menggunakan uji-t independen ini dilakukan untuk mengetahui perbedaan pengaruh olahraga bersepeda dalam menurunkan derajat dismenore kelompok perlakuan maupun kelompok kontrol pada mahasiswi Fakultas Kedokteran Universitas 
Muhammadiyah Malang angkatan 2008. Dengan tingkat kepercayaan sebesar $95 \%$, hasil analisis data tersebut terdapat pada tabel berikut :

Tabel 5. Hasil Analisis Uji-t Independen

\begin{tabular}{|c|c|c|c|}
\hline & t-hitung & $\overline{\mathrm{Df}}$ & Signifikansi \\
\hline $\begin{array}{l}\text { Kelompok } \\
\text { Perlakuan- } \\
\text { Kelompok Kontrol } \\
\text { Dismenore } \\
\text { sebelum }\end{array}$ & 1,058 & 36 & 0,297 \\
\hline $\begin{array}{l}\text { Kelompok } \\
\text { Perlakuan- } \\
\text { Kelompok Kontrol } \\
\text { Dismenore setelah }\end{array}$ & 2,440 & 36 & 0,020 \\
\hline
\end{tabular}

Derajat dismenore sebelum antara kelompok perlakuan dan kelompok kontrol didapatkan nilai signifikan $>\alpha=$ 0,05, sehingga dapat disimpulkan terima $\mathrm{H} 0$ atau tolak $\mathrm{H} 1$ yang berarti bahwa tidak terdapat perbedaan yang signifikan antara kelompok perlakuan dan kelompok kontrol terhadap derajat dismenore sebelum melakukan olahraga bersepeda. Beda halnya dengan derajat dismenore setelah melakukan olahraga bersepeda dimana nilai signifikansi $<\alpha=0,05$, sehingga dapat disimpulkan tolak $\mathrm{H} 0$ atau terima $\mathrm{H} 1$ yang berarti bahwa terdapat perbedaan yang signifikan antara kelompok perlakuan dan kelompok kontrol terhadap derajat dismenore setelah melakukan olahraga bersepeda.

Untuk mengetahui pengaruh dan besar pengaruh olahraga bersepeda terhadap penurunan derajat dismenore pada kelompok perlakuan dilakukan uji-t berpasangan dan korelasi rank.

Berdasarkan uji-t berpasangan untuk kelompok perlakuan diatas, didapatkan nilai signifikansi 0,000 yang lebih kecil daripada $\alpha=0,05$, sehingga dapat disimpulkan bahwa olahraga besepeda berpengaruh terhadap penurunan derajat dismenore pada mahasiswi Fakultas Kedokteran Universitas Muhammadiyah Malang angkatan 2008. Dari pengujian tersebut untuk mengetahui besar pengaruhnya olahraga bersepeda terhadap penurunan derajat dismenore dilanjutkan dengan pengujian korelasi rank.

Tabel 6. Hasil Analisis Korelasi rank

\begin{tabular}{l|l}
\hline Korelasi hitung & Sig / p \\
\hline 0,814 & 0,000 \\
\hline
\end{tabular}

Korelasi rank $=(0,814)^{2} \times 100 \%=0,662596 \times$

$$
100 \%=66,3 \%
$$

Didapatkan nilai korelasi hitung sebesar 0,814, kemudian dikuadratkan dan diprosentasekan, dengan hasil akhir sebesar 66,3\% yang berarti pengaruh olahraga bersepeda terhadap penurunan derajat dismenore sebesar $66,3 \%$.

Rancangan penelitian yang dipergunakan adalah observasi analitik dengan pendekatan secara kohort. Bab ini berisi pembahasan mengenai penelitian pada mahasiswi Fakultas Kedokteran Universitas Muhammadiyah Malang angkatan 2008 yang mengalami dismenore sebanyak 45 atau sebesar $62,5 \%$ dari total 72 mahasiswi, namun yang termasuk dalam kriteria inklusi hanya 38 mahasiswi yang telah dibagi menjadi 19 kelompok perlakuan dan 19 kelompok kontrol. Kemudian data diperoleh dengan menggunakan kuisioner yang bertujuan untuk mengetahui pengaruh olahraga bersepeda dalam menurunkan derajat dismenore pada mahasiswi Fakultas Kedokteran Universitas Muhammadiyah Malang angkatan 2008.

Berdasarkan hasil penelitian didapatkan bahwa kelompok perlakuan yang rutin melakukan olahraga bersepeda (2-3x/ minggu, 30-60 menit) selama 1 bulan mengalami penurunan derajat dismenore sebesar $78,9 \%$ atau sebanyak 15 mahasiswi. Sedangkan pada kelompok kontrol sebesar 84,2\% atau sebanyak 16 mahasiswi derajat dismenorenya tetap. Hal ini didukung oleh penelitian yang dilakukan Putri Leilina (2008) yang mendapatkan hasil bahwa olahraga memberikan efek untuk menurunkan angka kejadian dismenore. Hal tersebut juga sesuai dengan Ramaiah (2006) yang menyebutkan bahwa, salah satu cara yang sangat efektif untuk mencegah nyeri dismenore adalah melakukan aktivitas olahraga aerobik karena dapat meningkatkan pasokan darah ke organ reproduksi sehingga memperlancar peredaran darah dan meningkatkan pelepasan hormon endorphine, yaitu hormon penghilang nyeri alami ke aliran darah sehingga dapat mengurangi derajat dismenore.

Adapun hasil analisis data menggunakan uji-t berpasangan yang dilakukan menggunakan program SPSS statistik 17.0 untuk menguji hipotesis. Dari hasil uji-t berpasangan dengan tingkat kepercayaan $95 \%$ dan $p<0,05$ didapatkan nilai signifikan sebesar 0,000 kemudian untuk mengetahui seberapa besar pengaruh olahraga bersepeda terhadap penurunan derajat dismenore, dihitung dengan menggunakan tabel korelasi rank dengan hasil akhir sebesar $66,3 \%$ yang berarti olahraga bersepeda berpengaruh dan besar pengaruhnya sebesar $66,3 \%$ dalam menurunkan derajat dismenore pada mahasiswi Fakultas Kedokteran Universitas Muhammadiyah Malang angkatan 2008. Hal ini sesuai dengan penelitian yang dilakukan oleh Abbaspour (2006) dimana keparahan dan durasi dismenore berkurang dengan adanya olahraga $(\mathrm{p}<0,01)$.

Olahraga bersepeda dapat menurunkan derajat dismenore karena olahraga bersepeda merupakan salah satu dari macam olahraga aerobik dan merupakan olahraga yang mempunyai unsur rekreasi dan relaksasi. Olahraga bersepeda dapat menghasilkan hormon endorphine. Endorphine adalah neuropeptide yang dihasilkan tubuh pada saat relaks/ tenang. Endorphine dihasilkan di otak dan susunan syaraf tulang belakang. Hormon ini dapat berfungsi sebagai obat penenang alami yang diproduksi otak dimana dapat memberikan rasa nyaman dan mengurangi rasa nyeri pada saat kontraksi endometrium. Olahraga bersepeda terbukti dapat meningkatkan kadar hormon endorphine empat sampai lima kali dalam darah. Sehingga, semakin banyak melakukan olahraga besepeda maka akan semakin tinggi pula kadar hormon endorphine dalam darah. Ketika seseorang melakukan olahraga bersepeda maka akan memberikan rangsangan proprioseptif, yang akan ditransmisi melalui serabut besar ke formatio reticularis, thalamus dan sistem limbik, dari sini akan terjadi pelepasan endorphine, yang akan mengaktifkan suatu jalur inhibisi nyeri desendens (ke aliran darah) dan menghambat transmisi serta pengaturan nyeri sehingga dapat mengurangi derajat dismenore. Selain itu olahraga bersepeda juga meningkatkan efesiensi kerja paru, paningkatkan jumlah dan ukuran pembuluh darah sehingga 
oksigen dan aliran darah dapat tersalurkan ke organ reproduksi yang mengalami vasokonstriksi (Kuntaraf, 1992).

Dari data deskripsi pengaruh olahraga bersepeda dalam mengurangi derajat dismenore (Tabel 5.1.3), diketahui bahwa 4 mahasiswi atau sebesar $21,1 \%$ dari kelompok perlakuan derajat dismenorenya tetap atau tidak mengalami penurunan sekalipun telah melakukan olahraga secara rutin selama 1 bulan. Pada kelompok kontrol, didapatkan 1 mahasiswi atau sebesar 5,3\% derajat dismenorenya bertambah. Hal ini sangat mungkin terjadi kerena pengaruh dari faktor stress. Tubuh bereaksi saat mengalami stress. Faktor stress ini dapat menurunkan katahanan terhadap rasa nyeri. Tanda pertama yang menunjukkan keadaan stress adalah adanya reaksi yang muncul yaitu penegangan otot tubuh individu dipenuhi oleh hormon stress yang menyebabkan tekanan darah, detak jantung, suhu tubuh, dan pernafasan meningkat. Disisi lain saat stress, tubuh akan menghasilkan hormon adrenalin yang kemudian diikuti dengan lepasnya hormon estrogen, pelepasan hormon stress adrenalin yang diikuti dengan lepasnya hormon seks entrogen disebabkan karena pada wanita yang sedang tidak hamil, selain diproduksi di ovarium estrogen juga diproduksi oleh korteks adrenal yang merupakan tempat produksi hormon adrenalin (Sheerwood, 2001). Estrogen dapat menyebabkan peningkatan kontraksi uterus secara berlebihan, peningkatan kontraksi secara berlebihan ini menyebabkan rasa nyeri. Selain itu hormon adrenalin juga meningkat sehingga menyebabkan otot tubuh tegang termasuk otot rahim dan dapat menjadikan nyeri ketika menstruasi (Wang, 2004). Disamping itu 4 mahasiswi kelompok perlakuan derajat dismenorenya tetap dan 1 mahasiswi dari kelompok kontrol derajat dismenorenya bertambah, hal tersebut kemungkinan juga dapat dikarenakan dismenore yang mereka alami adalah dismenore sekunder. Sejalan dengan Simanjuntak (2005) yang mengatakan bahwa dismenore yang pada mulanya disangka primer, kadangkala setelah dilakukan pemeriksaan lebih lanjut menunjukkan adanya kelainan organik. Menurt Baziad, dkk (2005) dismenore sekunder terjadi karena adanya kelainan patologi (organik) dalam pelvis. Dismenore ini disebut juga dismenore organik, dapatan (akuisita) atau ekstrinsik. Kelainan ini dapat timbul setiap saat dalam perjalanan hidup. Meskipun dismenore sekunder timbul akibat lesi yang luas, nyerinya lenyap diantara masa haid, dismenore sekunder ini biasanya hanya dapat diterapi dengan pembedahan atau thermoablasia untuk menghilangkan kelainan organik yang diderita. Dan pada kelompok kontrol, terdapat 2 mahasiswi atau sebesar $10,5 \%$ yang mengalami penurunan derajat dismenore sekalipun tidak melakukan olahraga bersepeda secara rutin selama 1 bulan, hal tersebut kemungkinan karena faktor nutrisi. Menurut French (2005) Selain medikamentosa mengatasi dismenore dapat dilakukan dengan terapi nonmedikamentosa salah satunya adalah terapi nutrisi. Perubahan pada pola makan atau diet dapat membantu mengurangi atau mengobati dismenore, antara lain adalah : Peningkatan masukan makanan seperti serat, kalsium, makanan dari bahan kedelai, buah-buahan dan sayuran; mengurangi konsumsi makanan yang memicu sindrom premenstrual seperti kafein, garam dan gula; berhenti merokok karena memperburuk kram dan mengkonsumsi suplemen multivitamin dan mineral yang mengandung kadar magnesium dan vitamin B6 (piridoksin) yang tinggi setiap hari, dan suplemen minyak ikan (fish oil) (Tran, 2001). Menurut werbach (2004), adanya peningkatan permeabilitas kapiler oleh vitamin c akan meningkatkan efek vasodilatasi dari niasin. Vitamin E menghambat pelepasan tromboksan A2 dan menstimulasi sintesis prostasiklin, sedangkan magnesium mempunyai efek vasodilator dan efek merelaksasikan otot serta menghambat sistesis prostaglandin F2 alfa (PGF2 $\alpha$ ).

\section{SIMPULAN}

Sebanyak 45 atau sebesar 62,5\% dari total 72 Mahasiswi Fakultas Kedokteran Universitas Muhammadiyah Malang angkatan 2008 mengalami dismenore. Derajat dismenore terbanyak sebelum melakukan olahraga bersepeda, untuk kelompok perlakuan sebanyak 6 mahasiswi atau sebesar 31,6 $\%$ mengalami derajat dismenore sedang (skala 6 VAS) dan kelompok kontrol sebanyak 7 mahasiswi atau sebesar 36,8 $\%$ juga mengalami derajat dismenore sedang (skala 6 VAS). Derajat dismenore terbanyak untuk kelompok perlakuan setelah melakukan olahraga bersepeda adalah derajat ringan (skala 2 VAS) yaitu sebanyak 9 mahasiswi atau sebesar 47,7\%. Untuk kelompok kontrol terbanyak adalah derajat sedang (skala 6 VAS) yaitu sebanyak 8 mahasiswi atau sebesar 42,1\%. Perbedaan derajat dismenore sebelum dan setelah melakukan olahraga bersepeda antara kelompok kontrol dan kelompok perlakuan adalah 15 mahasiswi atau sebesar 78,9\% kelompok perlakuan mengalami penurunan derajat dismenore, 16 mahasiswi atau sebesar 84,2\% kelompok kontrol derajat dismenorenya tetap. Olahraga bersepeda berpengaruh dalam menurunkan derajat dismenore pada mahasiswi Fakultas Kedokteran Universitas Muhammadiyah Malang angkatan 2008 dengan nilai signifikan uji-t berpasangan sebesar 0,000. Nilai hasil uji korelasi rank sebesar 66,3\%, yang berarti bahwa besar pengaruh olahraga bersepeda dalam menurunkan derajat dismenore sebesar $66,3 \%$.

\section{DAFTAR PUSTAKA}

Abbaspour, Z, Rostami, M and Najjar, Sh, 2006. The Effect of Exercise on Primary Dysmenorrhea. J Res Health Scin 6(1), pp. 26-31.

Afriwardi, 2010. Ilmu Kedokteran Olahraga. Jakarta: EGC, hal 27-47.

Andira, D, 2010. Seluk- beluk Kesehatan Reproduksi Wanita. (1). Jogjakarta : A*PLUS BOOKS, hal. 32.

Annathayakeishka, 2009. Nyeri haid. Available from http:/ /forum.dudung.net $/$ index.php?action = printpage; topic $=14042.0$, diakses tanggal 10 Oktober 2011.

Baziad Ali et.al, 2005. Aspek Patofisiologi dan Penatalaksanaan Dismenore. Dalam: Baziad Ali et.al. Endokrinologi Ginekologi. Jakarta: Kelompok Studi Endokrinologi Reproduksi Indonesia (KSERI), hal.71101.

Brunk, Doug, 2005. Thermoablation: 73\% have reduced dysmenorrheal at 3 years. San Diego Bureau: CBS.Available from: http://findarticles.com/p/articles/ mi_m0CYD/is_23_40/ai_n27863052/, diakses tanggal 30 September 2011. 
Burke, Edmund. R, 1996. High tech Cycling. First Edition : Human Kinethics Publisher Inc, pp. 23.

Calis KA., 2009. Dysmenorrhea. E-medicine Obstetrics and Gynecology. Available from: http://emedicine. medscape.com/article/253812-overview, diakses tanggal 21 Oktober 2011.

Chandran, Lahta, 2008. Menstruation Disorders: Overview. E-medicine Obstetrics and Gynecology. Available from: http://emedicine.medscape.com/article/953945overview/, diakses tanggal 24 Oktober 2011.

Chudnoff, Scott G., 2005. Dysmenorrhea. Medscape Ob/ Gyn \& Women's Health. Available from: http:// www.medscape. com/files/feeds/asktheexperts_ 3.xml/, diakses tanggal 13 Maret 2011.

Colin, Caroline M., and Shushan, Asher, 2007. Complications of Menstruation: Abnormal Uterine Bleeding. In: DeCherney, Alan H. ed, Nathan, Lauren ed. Current Diagnosis and Treatment Obstetrics and Gynecology 10th edition. United States of America: McGrawHill, pp. 572-573.

Dariyo, 2003. Panduan Lengkap Bugar Total. Jakarta: PT. Raja Grafindo Persada, hal. 10-13.

Edmundson, Laurel D., 2006. Dysmenorrhea Overview. Emedicine Emergency Medicine. Available from: http:/ /emedicine. medscape.com/article/795677-overview/, diakses tanggal 20 Oktober 2011.

French, Linda, 2005. Dysmenorrhea. American Family Physician 71(2), pp.285-291.

F.J. Monks, Koers, Haditomo.S.R, 2002. Psikologi perkembangan : pengantar dalam berbagai bagiannya. Yogyakarta : Gadjah Mada University Press, hal. 12.

Giriwijoyo, Y.S. Santoso, 2002. Ilmu faal olahraga. Bandung: FPOK,UPI, hal.2.

Hanafiah, Mohammad Jusuf, 2005. Haid dan Siklusnya. Dalam: Wiknjosastro, Hanifa ed, Saifuddin, Abdul Bari ed, Rachimhadhi, Trijatmo ed. Ilmu Kandungan edisi ketiga. Jakarta: Yayasan Bina Pustaka Sarwono Prawirohardjo, hal. 103-114.

Harry, 2007. Mekanisme endorphin dalam tubuh. Available from Http:/klikharry. files. wordpress. com/2007/ 02/1.doc + endorphin + dalam + tubuh, diakses tanggal 14 Juli 2011.

Hart, David McKay, and Norman, Jane, 2000. Abnormalities of Menstruation. In: Hart, David McKay and Norman, Jane. Gynaecology Illustrated 5th edition. China: Hartcourt Publishers, pp. 129-131.

Izzo A, and Labriola D, 1991. Dysmenorrhea and Sports Activity in Adolescents. Clin Exp Obstet Gynecol 18(2), pp.109-116.

Kristiono, 2007. Perkembangan psikologi remaja.. Available at Http :// Kristiono. wordpress.com/2008/04/23/ perkembangan- psikologi-remaja/, diakses tanggal 17 November 2011.

Kuntaraf KL, Kuntaraf J, 1992. Olah raga sumber kesehatan. Bandung: Indonesia Publishing House, hal. 47-83.

Latthe P et al, 2006. Factors Predisposing Women to Chronic Pelvic Pain: Systematic Review. BMJ 332(7544), pp. 749-755.

Lefebvre et al, 2005. Primary dysmenorrhea consensus guideline. J Obstet Gynaecol Can.
Moeloek D, Tjokronegoro A, 1984. Kesehatan dan olahraga. Jakarta: Fakultas Kedokteran UI, hal. 1-31.

Notoadmojo, S, 2005. Metodologi penelitian kesehatan. Jakarta : Rineka Cipta, hal. 38.

Nurali, Imran A., Kirana Ratna, Mulyatim, et al, 2006. Pedoman Kesehatan Olahraga di Puskesmas. Jakarta: Dinas Kesehatan, pp. 10.

Proctor M, Farquhar C., 2006. Diagnosis and management of dysmenorrhoea. BMJ 332, pp. 1134-8

Potter\& Perry, 2006. Buku Ajar Fundamental Keperawatan. Edisi 4. Jakarta : Penerbit Buku Kedokteran EGC, hal. 35-36.

Puji, Istiqomah, 2009. Pengaruh Senam Dismenore Dalam Mengurangi Dismenore Pada Remaja Putri Di SMU N 5 Semarang. S1 Skripsi. Universitas Muhammadiyah Semarang.

Sastroasmoro S, Ismael S, 1995 . Dasar-dasar Metodologi Penelitian Klinis. Jakarta: Binarupa Aksara, hal. 42-51

Sheerwood L., 2001. Fisiologi manusia dari sel ke sistem. 2nd ed. Jakarta: EGC, hal. 633-732.

Simanjuntak, Padapotan, 2005. Gangguan Haid dan Siklusnya. Dalam : Wiknkosastro, Hanifa ed, Saifuddin, Abdul Bari ed, Rachimhadhi, Trijatmo ed. Ilmu kandungan edisi ketiga. Jakarta: Yayasan Bina Pustaka Sarwono Prawirohardjo, pp. 229.

Sumudarsono, S, 1998. Pengetahuan praktis kesehatan dalam olahraga. Jakarta : PT.Gramedia, hal. 19.

Tran, Mai, 2001. Dysmenorrhea. Gale Encyclopedia of Alternative Medicine. Available from: http:// findarticle.com/p/articles/mi_g2603/is_0003/ ai_2603000333/, diakses tanggal 30 Oktober 2011.

Triangto, Michael, 2005. Jalan sehat dengan sports therapy. Jakarta: PT.Gramedia, hal 23-39.

Wagito, 2010, Manfaat Vitamin E Sebagai Pengobatan Dismenore Primer Pada Remaja Perempuan Pubertas, Tesis, Universitas Sumatra Utara, Sumatra Utara.

Wang L et al, 2004. Stress and dysmenorrhoea: a population based prospective study. Occup Environ Med, pp. 1021-1026.

Warianto, Melya, 2008. Akupuntur untuk Dismenore. Indonesia: Wordpress. A vailable from: http:// doktermelya. dagdigdug. com/2008/12/16/akupunturuntuk-dismenore/, diakses tanggal 22 Oktober 2011.

Werbach, Melvin R., 2004. Nutrients in the Treatment of Dysmenorrhea. California: CBS. Available from: http:/ / findarticles.com/p/articles/mi_hb4365/is_14_37/ ai_n29114370/, diakses tanggal 11 Oktober 2011.

Widjanarko, Bambang, 2006. Dismenore: Tinjauan Terapi pada Dismenore Primer. Majalah Kedokteran Damianus 5(1), hal.11.

Wijayanti, Daru, 2009. Fakta Penting Seputar Kesehatan Reproduksi Wanita. Jogyakarta : Book Marks, hal. 16-17.

Wiknjosastro. H, 2005. Ilmu kandungan. Jakarta : Yayasan bina pustaka, hal. 112-114.

Wong, OL, 1999. Whaley and Wong's Nursing Care of Infants and Children. Edisi ke-6. New York : Mosby, pp. 60.

Zoler, Mitchel L., 2004. Oral Contraceptives Cut Pain in Adolescent Dysmenorrhea. Philadelphia: CBS. Available from: http://findarticles.com/p/articles/ mi_hb4365/is_14_37/ai_n29114370/, diakses tanggal 23 Oktober 2011. 